\title{
O LIVRO DIDÁTICO HISTÓRIA DO BRASIL E A HISTÓRIA A SER ENSINADA DE BORGES HERMIDA (1942-1971)
}

\author{
The textbook History of Brazil and the History to be teached by Borges \\ Hermida (1942-1971) \\ El libro didáctico Historia del Brasil y la Historia a ser enseñada de Borges \\ Hermida (1942-1971)
}

Diogo dos Santos Brauna ${ }^{1}$

\begin{abstract}
Resumo
Este artigo investigou o livro didático intitulado História do Brasil, do autor Antônio José Borges Hermida, durante o período de 1942 a 1971. O objetivo central foi entender quais concepções de História e de ensino de História foram veiculadas pelo autor e sua obra. Uma das contribuições apresentadas foi o papel desempenhado pelas editoras na veiculação de padrões específicos de História ensinada. Para a análise do livro e da documentação editorial foram fundamentais os trabalhos de Chartier (1988), Munakata (1997) e Bittencourt (1993).
\end{abstract}

PALAVRAS-CHAVE: Livro didático. Ensino de História. História do Brasil

\begin{abstract}
This article investigated the textbook entitled the History of Brazil, by the author Antônio José Borges Hermida, during the period from 1942 to 1971. The main purpose of this research was to understand which conceptions of History and History teaching were published by the author and his work. One of the contributions presented in this research was the role played by publishers in ad specific patterns of History taught. For the analysis of textbook History of Brazil, the main object and source of this research and editorial documentation were instrumental in the work of Chartier (1988), Munakata (1997) and Bittencourt (1993).
\end{abstract}

KEYWORDS: Textbook. History Teaching. History of Brazil

\section{Resumen}

Este artículo investigó el libro didáctico intitulado Historia del Brasil, del autor Antonio José Borges Hermida, durante el período de 1942 hasta 1971. El objetivo central fue comprender cuales concepciones de la Historia y de enseñanza de Historia fueron vehiculados por el autor y su obra. Una de las contribuciones presentadas fue el papel desempeñado por las editoras en vehículacion de padrones específicos de Historias enseñadas. Para el análisis del libro y de la documentación editorial fueron fundamentales los trabajos de Chartier (1988), Munakata (1997) y Bittencourt (1993).

PALABRAS CLAVE: Libro didáctico. Enseñanza de Historia. Historia de Brasil

\section{INTRODUÇÃO}

\footnotetext{
${ }^{1}$ Mestre em Educação: História, Política, Sociedade (PUC-SP). Professor da Universidade Santo Amaro (UNISA). E-mail: dbrauna@prof.unisa.br.
} 
O presente texto investiga as concepções de História veiculadas pelo livro História do Brasil, do autor Antônio José Borges Hermida, bem como sua proposta de História a ser ensinada. ${ }^{2}$ Para tanto, problematiza a organização formal do livro e as estratégias editoriais, responsáveis pela identidade visual e por sua longa circulação no mercado editorial.

Durante todo o período de circulação no mercado o livro esteve sob o selo de três editoras diferentes. Na década de 1950, pela Editora do Brasil, como uma coleção, e por um curto período pela Codil Edições, uma gráfica prestadora de serviços. Na década de 1960 e 1970, consolidou-se na Companhia Editora Nacional (CEN) atingindo o ápice de sua circulação, tornando-se um dos Livros Didáticos (LD) de História mais vendidos.

Ao longo de seus quase cinquenta anos de circulação no mercado editorial através das várias edições e reimpressões ${ }^{3}$, o livro sobreviveu a diversas reformas educacionais e mudanças políticas, além das questões de mercado e das transformações na indústria gráfica brasileira. Sobreviveu também, as diversas concepções pedagógicas e de ensino de História veiculadas.

Como foi possível um livro sobreviver tanto tempo em um mercado editorial em expansão e aos diversos desafios políticos e educacionais, além das próprias transformações nas concepções de História? Qual o segredo do seu sucesso editorial? Quais foram os impactos dessa longa circulação para o ensino de História? Para responder a estes e outros questionamentos, o próprio livro didático é uma fonte privilegiada.

Para a composição do presente texto foram realizadas algumas considerações sobre os estudos que tomaram o livro didático como objeto de estudo, ressaltando suas potencialidades e transformações nos olhares, especialmente com o surgimento da História do Livro e da Leitura. São apresentados também os conceitos de Disciplina Escolar e Cultura Escolar, surgidos em meados da década de 1990, e que possibilitaram uma virada significativa nos estudos sobre as disciplinas escolares. Posteriormente, é analisada a trajetória do livro, os debates sobre o ensino de História nas décadas de 1950 e 1960 e a proposta de História a ser ensinada de Borges Hermida. Por fim, são estabelecidas algumas considerações sobre a trajetória do livro.

\section{Estudando Livros Didáticos: um breve percurso historiográfico}

As pesquisas que abordaram Livros Didáticos (LD) até os anos de 1990 se concentraram no aspecto ideológico e na acumulação de capital das editoras, entendendo-os como objetos prontos, já que supostamente visam o conhecimento e o aprendizado. Dentre estas visões, também ganharam destaque aquelas que buscaram identificar no LD a representação de determinados sujeitos históricos, como o negro, o bandeirante, o escravizado, dentre tantos outros.

Estes trabalhos não consideravam a ideia de que o livro é um produto manufaturado feito por "escribas e outros artesãos, por mecânicos, engenheiros, e por impressoras e outras

\footnotetext{
${ }^{2} \mathrm{O}$ texto atual apresenta parte dos resultados da dissertação de mestrado intitulada O livro História do Brasil de Borges Hermida: uma trajetória de edições e ensino de História (1942-1971), defendida no ano de 2013 pelo Programa de Estudos Pós-graduados em Educação: História, Política, Sociedade, da PUC-SP.

${ }^{3}$ Através do banco de dados de livros escolares brasileiros (LIVRES), do acervo da Biblioteca Nacional do Rio de Janeiro e de sebos virtuais, foi possível reunir diversas edições do livro. Para a primeira série ginasial, por exemplo, em 1961 o livro atingiu a 53ª edição. Percebe-se que o livro sofreu diversas intervenções editoriais para adequar-se aos novos desafios que se apresentavam.
} 
máquinas". Por consequência, consideravam apenas os elementos dos autores e da escrita. Estavam ausentes nestes estudos "as intenções e os dispositivos" característicos das transformações do escrito "a livro ou a impresso, produzidas pela decisão editorial ou pelo trabalho da oficina” (CHARTIER, 1988, p. 127).

Somente a partir dos anos de 1990 novas pesquisas começaram a considerar que o livro é objeto de construção coletiva, cujo circuito é longo e inclui estratégias de circulação no mercado editorial. Estas transformações ocorreram, sobretudo, com o surgimento dos aportes teóricos da História Cultural do livro e da leitura. Autores como Carlo Ginzburg, Robert Darnton, Roger Chartier e Jean Hebrard, entre outros, tornaram-se referências indispensáveis para as produções historiográficas das últimas décadas.

Diante desta perspectiva, analisar um livro implica em considerar todos os elementos que colaboram para sua existência material. Isto requer considerar as escolhas feitas por editores e outros profissionais na composição dos aspectos que caracterizam o livro e, consequentemente, moldam sua identidade (MUNAKATA, 1997, p. 88).

Igualmente, o emprego de aportes teóricos de autores da área de currículo (Ivor Goodson e Michael Apple, por exemplo) e dos conceitos de Cultura Escolar e Disciplina Escolar (Dominique Julia e Andre Chervel, entre outros), contribuíram para que os estudos sobre a escola fossem vistos de modo mais amplo e compostos por uma rede extensa de sujeitos envolvidos (BITTENCOURT, 2001, p. 15).

Contrapondo-se à ideia de transposição didática, proposta por Yves Chevallard, autores como Chervel (1990) e Julia (2001; 2002) argumentam que as disciplinas escolares não são fruto apenas das imposições sociais e culturais, mas produto de uma "cultura própria e complexa, historicamente construída". A Cultura Escolar, portanto, pode ser entendida como "um conjunto de normas que definem conhecimentos a ensinar e condutas a inculcar, e um conjunto de práticas que permitem a transmissão desses conhecimentos e a incorporação desses comportamentos" (JULIA, 2001, p. 10).

Esta mudança de olhar gerou a necessidade de novas fontes e objetos para investigar o interior e o exterior da escola. Dentre estas novas fontes e objetos, o livro didático tornou-se imprescindível, uma vez que se faz presente no cotidiano escolar, com exercícios, conteúdo a ser ensinado e, em alguns casos, instruções para seu uso e ensino da disciplina (MÁSCULO, 2008, p. 12). Logo, uma história do livro didático fundamentada na escola, pode auxiliar a compreensão de como é construído um saber escolar, percebendo com clareza os limites de intervenção dos professores e dos alunos no processo de produção de conhecimento (CHERVEL, 1990) ${ }^{4}$.

A primeira aparição do livro História do Brasil ocorreu no final da década de 1940. Neste período, a disciplina de História do Brasil se consolidaria como cadeira autônoma através da Reforma Gustavo Capanema (1942), nome do Ministro da Educação do governo Vargas. As primeiras edições da obra reportavam-se principalmente a portaria $\mathrm{n}^{\circ} 1045 / 51$, que detalhava o programa de estudos para o Ensino Ginasial, como consequência e desdobramento direto da Reforma Capanema.

Ao longo da década de 1970, com a reforma educacional instituída pela lei 5692/71, o livro entrou em declínio após atingir certa popularidade no mercado editorial nas décadas

\footnotetext{
${ }^{4}$ Apesar de imprescindível, o livro didático não é o único instrumento que faz parte da educação e do processo de ensino-aprendizagem. Ele estabelece relações com outros instrumentos que, ao concorrerem e complementarem influem necessariamente em suas funções e usos (Choppin, 2004, p. 553). No entanto, o livro didático ainda é a principal ferramenta do professor e aluno neste processo (ensino-aprendizagem), servindo como objeto e/ou fonte de investigação (Bittencourt, 1993).
} 
anteriores. A década de 1970 também apresentou inovações significativas no mercado editorial e no ensino de História, quando surgiram livros e coleções com propostas diferenciadas, o que também contribuiu para o declínio da obra História do Brasil, mas não promoveu o seu desaparecimento do mercado.

Como autor de LD, a trajetória de Antônio José Borges Hermida parece ter sido realmente longa, "desde 1945 até o seu falecimento, dedicou a sua vida à produção de livros didáticos de História para o primeiro e segundo graus" (RIBEIRO, 2008, p. 56).

A licenciatura em História e Geografia pela Faculdade Nacional de Filosofia (FNFi), acompanhada de uma passagem pelo renomado Colégio Pedro II conferia-lhe certa credibilidade como autor, especialmente em um contexto de combate ao autodidatismo e ao consequente despreparo por parte dos professores sem formação adequada, razões apontadas para as mazelas da educação no discurso de grandes periódicos da década de 1950 (BERNARDES, 2010).

A historiografia abordou sua produção indiretamente, apresentando-o como um autor nacionalista, portador de uma concepção de História linear e positivista impregnada pela dualidade de termos como selvagens/civilizados e atrasados/avançados, que acabou obscurecendo os conflitos e apresentando uma ideia de nação pautada na homogeneidade das raças.

Ribeiro (2010), por exemplo, argumenta que a produção de autores como Borges Hermida, Joaquim Manoel de Macedo e Sérgio Buarque de Hollanda, possuem características comuns, verificáveis na escrita de LD até a década de 1980. Para ele, estes autores "forjaram" um sujeito racializado em seus discursos, fundamentado em eixos: "origens e classificação, relações sociais e familiares, usos e costumes, primeiros contatos e suas influências na obra colonial" e nacional (RIBEIRO, 2010, p. 78).

Quanto às fontes utilizadas por estes autores, predominavam textos de cronistas e de personalidades ilustres da história do Brasil, como padre Antônio Vieira, Jean de Léry e Hans Staden, além dos historiadores Francisco Adolfo Varnhagen e Capistrano de Abreu. Assim, ao produzirem uma versão da História fundamentada numa leitura clássica da formação do Brasil, acabaram por estabelecer uma tradição.

No caso específico de Hermida, sua visão sobre as crenças religiosas das populações indígenas, por exemplo, "lembrava muito a definição apresentada por Capistrano de Abreu, [na obra] Capítulos de História Colonial” (RIBEIRO, 2010, p. 82).

Pode-se concluir que, na visão de Ribeiro, Hermida era portador de certa herança ou tradição historiográfica, cuja gênese estava em autores como Varnhagen e Capistrano de Abreu. Porém, para o próprio Ribeiro, esta não era uma herança pertencente apenas a Borges Hermida, mas também verificável nas produções de outros autores de renome.

A produção historiográfica também estabeleceu uma aproximação entre Borges Hermida e outros autores, especialmente Joaquim Silva. Ribeiro Jr. (2007), comparando os LD de Hermida e os de Joaquim Silva, concluiu que o autor "também dividiu seu livro em 10 unidades", nomeando-os com os pontos da portaria que regulamentava o ensino 5 . Diferentemente de Hermida, que "subdividiu as 10 unidades em 45 tópicos", um além do que rezava a lei. Joaquim Silva, conclui ainda, também descreveu os eventos históricos, mas, diferente de Hermida, em alguns momentos "analisa o cenário social", e apresenta as

\footnotetext{
${ }^{5}$ A Portaria Ministerial no 1.045 de 14/12/1951 apresentava os pontos que deveriam ser contemplados no ensino de História em forma de lista, sem mais orientações. Era comum os livros didáticos apresentarem a lista da portaria logo nas primeiras páginas.
} 
controvérsias do estudo histórico, "tomando partido de uma explicação" no final (RIBEIRO JR., 2007, p. 71).

Másculo (2008), ao comparar a coleção Sérgio Buarque de Hollanda com a de alguns concorrentes da época, também sugere semelhanças entre Hermida e Joaquim Silva, mas destaca o aspecto gráfico. De acordo com o autor:

\begin{abstract}
Na mesma época [da coleção Sérgio Buarque de Hollanda], a Companhia Editora Nacional também editava os livros de Borges Hermida, que seguiam uma diagramação muito parecida com a dos livros de Joaquim Silva: ilustrações criadas pela própria editora, reprodução de algumas pinturas e texto explicativo, acompanhado de um questionário. As semelhanças eram tantas, que, ao deixarem de publicar o Joaquim Silva, muitas das ilustrações que compunham seus livros passaram a ser utilizadas nos Compêndios de História do Brasil e Geral, de Borges Hermida, como se pode constatar pela capa do volume publicado na década de 1980. Essas duas obras marcaram o ensino de História nos anos 1950 a 1970, e o livro de Borges Hermida, para a satisfação dos professores que apreciavam este estilo (MẤSCULO, 2008, p. 60)
\end{abstract}

Diante do excerto, percebe-se que a CEN, ao produzir uma coleção inovadora como a de Sérgio Buarque de Hollanda, visivelmente também editava LD com outros formatos em concorrência, criando assim, uma rede de materiais para vários gostos. Evidentemente, ao utilizar as ilustrações de Joaquim Silva nos livros de Borges Hermida, a editora produzia certa proximidade entre os autores, estratégia que visivelmente não deve ser atribuída apenas às concepções de História dos autores, mas também as estratégias editoriais empregadas.

\title{
2 A História a ser ensinada de Borges Hermida: entre vultos e episódios, a formação da mente e do espírito
}

Em um parecer elaborado pela Delegacia de Ensino de Governador Valadares, especificamente pelos Auxiliares Técnicos da $7^{a}$ Delegacia Regional de Ensino (DRE), é possível perceber que a obra História do Brasil possuía certa aceitação e era bem avaliada.

Sobre o conteúdo, o relatório de apreciação concluía que "o autor apresenta um programa de modo claro, acessível e de maneira sucinta, contendo, todavia, o essencial".

Quanto à forma de exposição, a mesma apreciação afirmava que "a obra é desenvolvida sob a forma de textos bem encadeados, que apresentam o mérito de trazer ao final de cada um, os sinóticos de revisão dos assuntos tratados e os exercícios de fixação. As ilustrações são coerentes e originais, despertando o interesse do leitor ". Contudo, o mesmo parecer relatava a preponderância da quantidade sobre a qualidade "fugindo, neste aspecto, à filosofia atual do Ensino." Este seria um dos prenúncios do declínio da obra (Parecer 04/79 de 23/11/1979, Dossiês da CEN).

As décadas de 1950 e 1960 compreenderam o período de grande aceitação e circulação da obra História do Brasil, sobretudo com o processo de expansão da escola pública, sendo Borges Hermida, um dos autores que mais venderam livros. Apesar de algumas avaliações positivas sobre conteúdo e forma, sua proposta estava em comunhão com os debates sobre a História, o ensino de História, e os métodos considerados adequados? 
Durante as décadas de 1940 e 1950, no contexto das Reformas ${ }^{6}$ e da expansão do Ensino Secundário, a disciplina de História transformava-se para uma adaptação às novas configurações curriculares. Essas décadas foram marcadas, ainda que isto não significasse o rompimento com os elementos constitutivos da disciplina no passado, por discussões que propunham novos métodos e técnicas, cuja finalidade era romper uma tradição bacharelesca que ainda permanecia.

Um dos campos onde este debate foi travado foram os periódicos, em grande parte revistas vinculadas às editoras de sucesso da época. Nelas, os professores secundários eram vistos, de um modo geral, como profissionais marcados pela "mediocridade, pelo descompromisso, indolência e pela falta de conhecimentos básicos para a atividade docente" (BERNARDES, 2010, p. 78).

Estas afirmações partiam de alguns professores que colaboravam para estes periódicos, geralmente oriundos ou vinculados as Faculdades de Filosofia. Em alguns casos, apresentavam certo desprezo por aqueles que não possuíam ligações com as Faculdades de Filosofia, não eram concursados e/ou buscavam formar-se através das revistas.

Havia também outro conflito latente, sendo a renovação das décadas de 1950 e 1960 direcionada para um "aprofundamento dos fundamentos científicos e do papel formadorcrítico da disciplina", que atingiu a escola secundária devido ao recrutamento dos docentes ser feito, ao longo deste período, priorizando os professores licenciados, que ainda não eram maioria, mas em quantidade "suficientemente" expressiva (NADAI, 1993, p. 155).

Além dos periódicos, com a formação da Universidade de São Paulo e da Universidade do Brasil, no Rio de Janeiro, uma nova tradição historiográfica formava-se e também reivindicava espaço no cenário do ensino de História. A crítica mais severa recaiu principalmente sobre o método com o qual a disciplina era lecionada há anos. Professores "secundários ou universitários, fossem diretores de escola ou autores de livros didáticos, fossem ligados ou não ao Estado, todos aqueles que se posicionavam defendiam este método, o ativo, considerado moderno e necessários [...]" (BERNARDES, 2010, p. 71).

Ora, quais eram as implicações da História do Brasil que vinha sendo ensinada há décadas e qual implicação trazia para o conhecimento histórico? O "fio condutor" dessa história ensinada estava centrado na figura do colonizador, ou seja, a do português e, depois, a do imigrante europeu. Africanos e indígenas, bases de nossa cultura, eram tratados como contribuições "paritárias". Daí a ênfase nos aportes civilizatórios, pois se restringia o Brasil à condição de país colonizado e as diferenças "nas condições de trabalho e de posição face à colonização das diversas etnias" (NADAI, 1993, p. 149).

O discurso histórico, em suma, produzia uma ideia da contribuição harmoniosa, sem violência e conflito, numa marcha progressiva de seus habitantes. $\mathrm{O}$ passado, ao mesmo tempo em que valorizava tais aspectos, também os legitimava (NADAI, 1993, p. 151).

Formação deficitária, mediocridade, acomodação. Essas eram algumas críticas que recaiam sobre o professorado. Munakata (2004), ao estudar a elaboração de dois manuais de

\footnotetext{
${ }^{6}$ As primeiras edições fazem referência às portarias $n^{\circ} 724 / 51,966 / 51$ e 1045/51, desdobramentos da Reforma Capanema (lei no 4024/42). Durante a década de 1960, o livro reportava-se à lei de 4024/61, instituída durante um contexto de fortes discussões e debates sobre a ampliação do ensino público. No final dos anos de 1960 e início da década de 1970, entraram em vigor as reformas educacionais 5540/68 e 5692/71. Estas leis foram implementadas durante a ditadura militar e, dentre outras modificações, acabaram com os exames de admissão, estabeleceram o ensino de primeiro grau com oito anos e o de segundo com três, além de instituírem as chamadas licenciaturas curtas. Estas medidas atendiam as crescentes reivindicações decorrentes da demanda pela educação pública, influenciando diretamente as produções didáticas do período.
} 
História para professores pela Caldeme, instituída por Anísio Teixeira em 1952, percebeu também o conflito de difícil solução entre um aporte "erudito" e o "pedagógico" da História, em um momento que a escola pública estava em rápida expansão e estendia-se pelos rincões do país. Este embate estabelecia um duelo entre os profissionais da História. De um lado, aqueles que privilegiavam a pesquisa e procuravam "libertar-se das preocupações com aspectos didáticos, preferindo tratar do assunto em "nível mais elevado". De outro, os professores, que não possuíam compreensão das questões "teóricas e metodológicas", logo, preferindo os tais "aspectos didáticos" (MUNAKATA, 2004, p. 528).

De acordo com os professores que escreviam nos periódicos e defendiam o método ativo, a escola e principalmente os professores deveriam utilizar-se de novas ferramentas. Atividades como excursões, visitas a museus ou coleções de objetos, realização de modelos ou maquetes, estudos dirigidos, entre outras atividades, fariam parte do que consideravam como método "moderno" de ensino (NADAI, 1993, p. 155).

Nos anos de 1960 esses problemas se acirraram, configurando-se numa época favorável à experimentação de novos métodos, currículos e conteúdos. Neste sentido, os debates promovidos pelos periódicos destacavam também como finalidades do ensino de História o seu potencial para a "explicação do presente" e para o "ensinar a viver". O ensinar a viver, no caso, significava "uma vida pessoal mais rica, eficiente e cheia de significado", com a finalidade bastante genérica de desenvolver a personalidade integral do estudante (BERNARDES, 2010, p. 42).

Ao estudar a obra História do Brasil de João Ribeiro, Hansen (2000) percebeu certa preocupação do autor com a formação de professores. A estratégia empregada no livro consistia na utilização de dois tipos de textos diferentes, cujo objetivo era "demarcar o que era destinado à leitura do aluno e o que era dirigido ao professor". Uma orientação de leitura fundamental para garantir o sucesso de sua proposta de ensino de História (HANSEN, 2000, p. 57). A estratégia detectada por Hansen revela que um autor, ao elaborar uma obra didática, mobiliza recursos que, muitas vezes, transcendem a ciência de referência e as concepções de ensino de uma época. São estratégias empregadas com o objetivo de conformar saberes, produzir leituras e interpretar de modo específico.

Hermida, ao selecionar determinados pontos a serem trabalhados, construiu uma ideia bastante específica de História e, sobretudo, de História do Brasil. Durante as décadas de 1950 e 1960, as suas obras dedicadas à primeira série do Ensino Ginasial, apresentavam 27 pontos distribuídos de acordo com os programas de estudos de 1951. O livro privilegiava certas unidades e pontos com uma quantidade maior de páginas e pequenas variações em relação às determinações legais.

A noção de causalidade estava presente na narrativa dos livros da primeira série, e na quarta série a ênfase recaiu sobre as comparações e controvérsias relativas a determinados temas, como o posto ocupado por Pedro Álvares Cabral ou mesmo a data exata do descobrimento do Brasil. Em ambos os casos, foi predominante o privilégio das datas, especialmente na primeira série.

Os capítulos dos livros para ambas as séries possuíam dez unidades e seguiram um padrão determinado, ou seja, um texto com alguns subitens, um quadro resumo e, em alguns casos, textos dedicados à leitura que, quase sempre, tratavam de episódios que evidenciavam certas qualidades ou hábitos dos personagens de nossa história.

Um bom exemplo é um trecho descrito na $46^{\circ}$ edição para a primeira série ginasial, em que Hermida ressalta uma característica bastante peculiar do segundo Governador Geral: 
D. Duarte da Costa não foi feliz em seu governo: primeiramente foi a questão com D. Pêro Sardinha. Depois foi a invasão dos franceses no Rio de Janeiro. D. Duarte da Costa não tinha recursos e nada pode fazer contra os invasores. Entretanto, $\underline{\mathbf{o}}$ governador possuía bom coração e tudo suportava com paciência. Nunca se valeu de sua autoridade para castigar seus inimigos. Conta-se que, certa vez, numa casa em Salvador, com janelas e portas cerradas, várias pessoas falavam mal de D. Duarte da Costa. Faziam em tão altas vozes que alguém, que ia passando pela rua, aproximouse da janela e apurou o ouvido: Falem mais baixo que o Governador pode ouvir e continuou seu caminho. Correram todos, abriram a janela para ver quem era e ficaram mudos de espanto: era o próprio governador (HERMIDA, 1956, p. 55, grifo nosso).

Estratégias desta natureza demonstravam preocupação com a relação entre alunos e professores em sala de aula, principalmente em despertar o interesse do aluno pelo aprendizado de História, além da formação da personalidade, levando a crer que o livro era uma obra de professor para professores, fugindo aos aspectos acadêmicos em prol da prática de sala de aula. Em outra atividade, por exemplo, constavam assinaturas de homens ilustres de Portugal e do Brasil que, além de possuírem a finalidade de preencher espaços vagos nas páginas, como um recurso do processo de intervenção editorial, também possuíam finalidades mais ligadas a sua proposta de ensino de História, exaltando certas personalidades consideradas ilustres e possibilitando ao aluno que também deixasse sua rubrica, desejando ser um homem de virtudes.

No ano de 1951, Borges Hermida publicou um artigo bastante revelador sobre sua concepção de História na revista da Editora do Brasil S/A (EBSA), intitulado Algumas sugestões sobre o ensino de História Geral e do Brasil.

A EBSA era uma publicação mensal lançada em 1947, quatro anos após a fundação da própria editora. Era um pequeno periódico educacional intitulado de Documentário do Ensino, surgido da necessidade de a Editora do Brasil incrementar um departamento específico para a educação, com o propósito de atender as demandas recebidas de várias regiões do país.

Como documentário, produzia seu próprio conteúdo, mas também transcrevia textos legislativos e notícias que considerava pertinentes à educação e de interesse dos profissionais que atuavam neste setor. Além de periódico de assinatura gratuita para os profissionais da educação que mostrassem interesse, configurava-se como um importante porta-voz da editora.

Desse modo, militava em prol da escola particular e do ensino religioso e, apesar de veículo de informação que se dizia neutro, tomava postura favorável à intervenção militar na política e de ataque a qualquer movimento social que contestasse a ordem vigente (BRAGHINI, 2010).

No artigo que escreveu para a revista, Hermida buscou colaborar com algumas sugestões para que o ensino de História fosse produtivo, ou melhor, que atingisse "o máximo do rendimento". Para tal, sua sugestão era o planejamento das aulas centrado em três pilares: o plano de curso, o plano de unidade, e o plano de aula.

Um dos problemas evidenciados por Hermida e que demandaria uma melhor organização dos planos era o "excesso de conteúdo dos programas" para algumas séries, cujo professor:

Nestas circunstâncias é obrigado a omitir os assuntos das últimas unidades, exatamente aqueles que maior interesse oferecem à cultura geral do aluno, porque se referem à Idade Contemporânea e são antecedentes de acontecimentos da atualidade. 
Mas, com o plano de curso, o professor, depois de calcular o número provável de aulas destinado ao ensino de História em todo o ano escolar, faz uma distribuição da matéria, reservando para uma só aula os assuntos que lhe pareçam intimamente relacionados ainda que tratados em capítulos diferentes (HERMIDA, 1951, p. 33).

Apesar das dificuldades em cumprir o programa, dada à quantidade excessiva de conteúdos, o bom andamento e sua consequente execução dependeriam fundamentalmente do professor, que deveria organizar e planejar adequadamente. Essa postura reforçava as críticas feitas por outros professores sobre a incapacidade do corpo docente, desleixado e despreparado.

Hermida sugere ainda, em algumas ocasiões, a inversão dos conteúdos trabalhados em "proveito da maior unidade para o curso". Uma boa estratégia seria dividir o plano de curso em dois, ou seja, por semestres, porque "procedendo assim os professores terão assegurado o mais fiel cumprimento do programa, porque durante as férias de junho, poderão modificar o plano do segundo semestre de acordo com o trabalho que já produziram" (HERMIDA, 1951, p. 34).

Para o plano de unidade, sugeria que o mestre apresentasse os objetivos, pois estes dariam "ao estudo da História sua verdadeira significação". Para Hermida, os objetivos eram a aura da História, deste modo, transcenderiam os próprios conteúdos, revelando a natureza da disciplina. Mas quais seriam os objetivos de determinados temas? Que conhecimentos, através da História, seriam estimulados? Nosso autor é bem enfático ao apresentá-los:

Com efeito, que vale aludir à Imprensa sem assinalar sua importância civilizadora, a Joana D'Arc sem acentuar a lição de patriotismo que se conclue de sua atuação na Guerra dos Cem Anos? Principalmente aqueles objetivos que contribuem para a formação moral da juventude, devem ser encarecidos, como a humildade de Jesus, $\underline{\mathrm{o}}$ idealismo dos Gregos, a generosidade de Caxias, para com os vencidos, a probidade de Feijó, a abnegação dos jesuítas. É necessário que a História seja a mestra da vida e não a enumeração aborrecida de episódios políticos e militares (HERMIDA, 1951, p. 34, grifo nosso).

De acordo com o excerto, para Hermida a História possuía a finalidade de educar o espírito. Seria uma ferramenta fundamental para ensinar e aprender com os grandes vultos os valores que deveriam reger a vida. $\mathrm{O}$ inovador, em termos de método, não estaria na forma como a História era trabalhada em sala de aula. O problema não residia totalmente na aula expositiva ou na memorização, mas também no foco político-militar e na pouca ênfase no aprendizado para a vida, principalmente, o aprendizado "moral". Deste modo, era necessário dar à História "missão eminentemente educadora, pondo em evidência os nomes e os feitos daqueles que contribuíram para o bem-estar social na Ciência, na Administração e em tantos outros setores" (HERMIDA, 1951, p. 34).

O professor deveria, portanto, privilegiar os exemplos de vida e as qualidades de certas personalidades. Não apenas as conquistas militares ou os grandes feitos deveriam ser ressaltados, mas os benefícios sociais e as obras no campo da ciência e da administração. $\mathrm{Na}$ concepção de Hermida, essas finalidades estavam em sintonia com os novos métodos que colocavam, supostamente, a escola como um aprendizado para a vida.

Quanto às aulas, recomendava o "mínimo essencial de datas, nomes e acontecimentos, isto é, o suficiente para a compreensão geral do assunto". Também indicava que o professor deveria evitar "um só processo didático", para não gerar "fadiga" e a "dispersão mental" do 
aluno. Para evitar a exposição oral demasiada, seria fundamental o professor recorrer aos "interrogatórios, a breves exercícios, à leitura de trechos do compêndio, feita e interpretada pelos próprios alunos, e até à explicação de gravuras, que devem ser mostradas à classe, quando originais e bastante nítidas" (HERMIDA, 1951, p. 34-35).

Percebe-se no discurso de Hermida uma concepção de ensino bastante prática, que pode ter contribuído para seu sucesso. Contudo, mesmo fazendo parte de um grupo de professores oriundo das Faculdades de Filosofia, sua proposta de mudança não atendia aos debates sobre o ensino nas décadas de 1940-1950 e era contraditória, tanto pelo conteúdo como pelos exercícios propostos nos livros, uma vez que reforçava o caráter político-militar criticado por ele em seu artigo para a revista EBSA.

No final dos anos de 1960 e início da década de 1970 sua proposta de História e principalmente de História ensinada já apresentava claros sinais de esgotamento. No entanto, por uma conjuntura de fatores, seus livros não desapareceriam do mercado. De acordo com correspondência interna da CEN direcionada ao gerente da filial do Rio de Janeiro:

\begin{abstract}
Compreendo perfeitamente suas preocupações com relação aos nossos livros que são minhas também. Sei que os velhos compêndios do Hermida a cada ano têm tido suas possibilidades diminuídas, sendo essencial o aparecimento de pelo menos um livro novo de boa potencialidade. Seria o livro do Sérgio [Sérgio Buarque de Hollanda], que, entretanto, está sofrendo dramaticamente os efeitos da famigerada reforma [lei 5692/71] e não poderá sair antes da reabertura das aulas. Com o exposto você vê que ainda este ano precisamos insistir com os velhos Hermida e [Joaquim] Silva, apesar de tudo (Carta datada de 05/01/73, Correspondências, Arquivos da CEN, grifo nosso).
\end{abstract}

De acordo com a correspondência, a "famigerada" Reforma instituída com a lei 5692/71, que alterou o regime de seriação e fundiu as disciplinas de História e Geografia em Estudos Sociais, dificultou o lançamento de novos livros, contribuindo também para que as obras de Borges Hermida continuassem no mercado, mesmo com suas limitações. Mesmo com a publicação da coleção Sérgio Buarque de Hollanda, a CEN manteria suas obras até os anos $1990^{7}$, ofertando padrões diferentes de livros e autores para um mercado em plena expansão.

\title{
CONSIDERAÇÕES FINAIS
}

Ao transitar pelas editoras, a obra História do Brasil conservou as características de uma produção típica do começo dos anos de 1950 e, especialmente a Companhia Editora Nacional (CEN), através de sua intervenção e estratégias de circulação, tornou a obra uma das mais vendidas entre os anos de 1950 e 1970. Todavia, ao conservar parte da produção da Editora do Brasil da década de 1950, contribuiu para a perpetuação de um modelo de produção didática que era duramente criticada por alguns profissionais da área.

\footnotetext{
${ }^{7}$ Ribeiro Jr (2007, p. 68), em nota de rodapé, reproduz um trecho de uma correspondência datada em 05 de maio de 1993, do então Diretor-Presidente da CEN Jorge Antônio Miguel Yunes. Na carta, endereçada a Hermida, o Diretor-Presidente informa que a Editora não tem mais interesse em republicar a obra História do Brasil. Os motivos alegados são as "dificuldades que assolam a economia brasileira, com profundos reflexos na área editorial". Vale destacar que os direitos das obras de Borges Hermida foram adquiridos pela editora FTD nesta mesma década.
} 
A proposta de História a ser ensinada de Hermida, apesar de não corresponder aos debates e ao modelo considerado moderno, teve grande aceitação no mercado em função da sua praticidade, mobilizando recursos para o trabalho diário da sala de aula.

Após o ano de 1993, com o fim do contrato com a CEN, os direitos da obra História do Brasil foram adquiridos pela editora FTD, que passou a publicar os livros de Hermida mesmo após sua morte, em 1995. Todavia, a editora fez emergir um novo autor. Um folheto publicitário da FTD em 1995 anunciava seu retorno, mas garantia que a coleção havia sido "atualizada" e recebido um "cuidadoso tratamento de texto e imagem", com a finalidade de manter sua principal característica: a objetividade (MUNAKATA, 2000, p. 290).

Ironicamente, um autor bastante criticado por fazer uma história conservadora tornouse um autor progressista.

\section{REFERÊNCIAS}

BERNARDES, Rodolfo Calil. O ensino secundário nas escolas brasileiras (1942-1961). Dissertação de mestrado. São Paulo: PUC-SP, 2010.

BITTENCOURT, Circe Maria Fernandes. Livro didático e conhecimento histórico: uma história do saber escolar. Tese de doutorado. São Paulo: USP, 1993.

Identidade nacional e ensino de História do Brasil. In: KARNAL, Leandro

(org). O livro didático na sala de aula. São Paulo: Contexto, 2001.

BRAGHINI, Kátya Mitsuko Zuquim. A vanguarda brasileira: a juventude no discurso da Revista Editora do Brasil S/A. Tese de doutorado. São Paulo: PUC-SP, 2010.

CHARTIER, Roger. A história cultural entre práticas e representações. Lisboa: Difel, 1988.

CHERVEL, André. História das disciplinas escolares: reflexões sobre um campo de pesquisa. Teoria \& Educação, Porto Alegre, vol. 2, 1990, p. 177-229.

CHOPPIN, Alain. História do Livro e das edições didáticas: sobre o estado da arte. Educação e Pesquisa - Revista da Faculdade de Educação da USP. Universidade de São Paulo, v. 30, n. 3, set/dez, 2004, p. 549-566.

HANSEN, Patrícia Santos. Feições \& Fisionomia: a História do Brasil de João Ribeiro. Rio de Janeiro: Access, 2000.

HERMIDA, A. J. B. História do Brasil. Quarta série ginasial. São Paulo: Editora do Brasil, 1948. 
. Algumas sugestões para o ensino de História Geral e do Brasil. Revista EBSA:

documentário do Ensino. São Paulo, v. 4, nº 39, 1951, p. 33-36.

. História do Brasil. Primeira série ginasial, 46. ed. São Paulo: Editora do Brasil,

1956.

197?. História do Brasil 1. São Paulo: Cia Editora Nacional.

JULIA, Dominique. A cultura escolar como objeto histórico. Revista Brasileira de História da Educação. Campinas: Autores Associados, 2001.

Disciplinas escolares: objetivos, ensino e apropriação. In: LOPES, Alice Casimiro; MACEDO, Elizabeth (org). Disciplinas e integração curricular: história e políticas. Rio de Janeiro: DP\&A, 2002.

MÁSCULO, José Cássio. A Coleção Sergio Buarque de Hollanda: livros didáticos e ensino de história. Tese de doutorado. São Paulo: PUC-SP, 2008.

MUNAKATA, Kazumi. Produzindo didáticos e paradidáticos. Tese de doutorado. São Paulo: PUC-SP, 1997.

Histórias que os livros didáticos contam, depois que acabou a ditadura no Brasil. In: FREITAS, Marcos Cezar (org). Historiografia brasileira em perspectiva. São Paulo: Contexto, 2000.

Dois manuais para professores: histórias de sua produção. Revista Educação e Pesquisa. São Paulo, v. 30, n. 3, set/dez, 2004, p. 513-529.

NADAI, Elza. O ensino de História no Brasil: trajetória e perspectiva. Revista Brasileira de História, n. 25/6. São Paulo, ANPUH, 1993, p. 143-162.

RIBEIRO, Renilson Rosa. Exóticos, infantis e submissos na colônia identitária: as representações dos negros nos livros didáticos de história do Brasil. Revista História \& Perspectivas, Uberlândia, v. 38, Jan/jun, 2008, p. 43-77.

. A questão do "outro" e os livros didáticos. Revista Fato \& Versões, v. 2, n. 4, jul/dez, 2010, p.75-88. 
RIBEIRO JR, Halferd Carlos. O sistema de ensino ginasial e livros didáticos: Interpretações da independência brasileira de Joaquim Silva entre 1946 e 1961. Dissertação de mestrado. Franca: UNESP-SP, 2007.

\section{Acervos:}

- Companhia Editora Nacional (CEN).

- Biblioteca do Livro didático (FE-USP).

- Biblioteca Nacional do Rio de Janeiro.

Recebido: 24/03/2017

Aprovado: 25/04/2017 